\title{
$\mathrm{IMO}$ 회원국 감사제도 대응을 위한 해기교육 강화방안에 관한 연구
}

\author{
이윤철* + † 박성호 \\ * 한국해양대학교 해사수송과학부 교수, † 한국해양수산연수원 교수
}

\section{A Study on the Enhancement of Maritime Education and Training to cope with IMO Member-state Audit Scheme}

\author{
Yun-Cheol Lee* • + Sung-Ho Park \\ * Division of Maritime Transportation Science, National Korea Maritime University, Busan 606-791, Korea \\ + Korea Institute of Maritime and Fisheries Technology, Busan 606-773, Korea
}

\begin{abstract}
요 약 : 그 동안 각종 IMO 협약의 채택에도 불구하고 인명 및 해양환경에 관련된 대형 선박사고가 발생하는 것은 기국이 의무를 충실히 이행하고 있지 않고 이로 인하여 IMO 협약들이 효과적으로 이행되지 않기 때문이다. 특히, 기국 중 해당 선박과 기국 간에 진정한 연계가 없는 기국에서는 자국 내 해사안전 및 환경보호를 담당할 인적, 구조적 조직이 잘 정비되어 있지 않기 때문에 협약의 이행이 제대로 이루어 지지 않고 있다. 이와 같은 배경으로 IMO에서는 2003년 11월 제23차 총회에서 자발적 회원국 감사제도에 관한 결의서 A.946(23)이 채택되었 고, 동 제도는 2009년 11월 총회 결의서 A.1018(26)의 채택으로 2015년에 강제화 될 예정이다. 따라서 이 연구에서는 IMO 회원국 감사제도 의 개요와 동 제도의 감사기준으로 사용하고 있는 강제협약 이행코드를 살펴보았다. 또한 2015년 회원국 감사제도의 강제화에 따른 당사국 의 의무와 책임에 대해 검토하였다. 이를 중심으로 우리나라의 해기교육기관이 회원국 감사제도의 강제화에 선제적으로 대응하기 위한 해기 교육 강화방안을 제안하였다.
\end{abstract}

핵심용어 : 국제해사기구, 회원국 감사제도, 자발적 회원국 감사제도, 강제협약 이행코드, 해기교육

Abstract : In spite of adoption of various IMO Conventions over the past, the reason why large vessel accidents related to human life and marine environment occur is that the IMO Conventions are not effectively implemented due to contravention of the conventions by flag states. In particular, the implementation of the conventions are not well being performed because some flag states having weak genuine link between them and vessels haven't set up proper personal and structural organizations in charge of maritime safety and marine environment protection. From this background, IMO Resolution A.946(23) on the voluntary IMO Member-state Audit Scheme was adopted at the 23rd Assembly in Nov. 2003 and the Scheme is expected to be executed compulsorily in 2015 through the adoption of the IMO Resolution A.1018(26) in Nov. 2009. Accordingly, this study examined outline of the IMO Member-state Audit Scheme and the Code for the Implementation of Mandatory IMO Instruments used for the audit standards of this scheme. In addition, this study reviewed the member-states' obligations and responsibilities according to the compulsory implementation of the member-state audit scheme in 2015. Based on this, this study suggested the enhancement measures for maritime education and training of maritime education institutions of the Republic of Korea to cope positively with compulsory implementation of the IMO Member-state Audit Scheme.

Key words : International Maritime Organization, Member State Audit Scheme, Voluntary IMO Member-state Audit Scheme, Code for the Implementation of Mandatory IMO Instruments, Maritime Education and Training

\section{1. 서 론}

국제해사기구(International Maritime Organization : 이하 에서는 'IMO'라 한다)는 1959년 1월 창설 이래 해상안전과 해 양오염방지를 위한 많은 국제협약, 코드, 결의서 등을 채택 시행하여 왔다. 그 결과 해상안전과 해양환경보호를 위한 물 적기준과 안전기준은 매우 높은 수준에 이르게 되었다. 그러
나 최근까지도 선박의 해양안전과 해양환경보호에 막대한 지 장을 초래하는 대형 해양사고가 발생하고 있고, 편의치적제도 및 이중등록선제도 등에 대한 기국과 선박간의 진정한 연계 가 도외시 되고 있다. 이는 일부 체약국들이 IMO 협약을 완 전하고 효과적으로 준수하지 못하고 있는 것에 그 원인이 있 는 것으로 판단되고 있다. 따라서 새로운 협약의 채택이나 기 존 협약의 개정보다는 각 체약국들이 현행의 각 협약을 완전

\footnotetext{
* 대표저자 : 종신회원, lyc@hhu.ac.kr 051)410-4249

† 교신저자 : 종신회원, sloptk@naver.com 051)620-5817
} 
하고도 효과적으로 적용하여 시행하도록 하는 조치가 필요하 게 되었다.

이러한 필요성에 의하여 $\mathrm{IMO}$ 는 2006년 9월부터 '회원국감 사제도'(Member State Audit Scheme : 이하에서는 'MAS'라 한다)를 시행하게 되었다. 이 과정에서 우리나라는 2007년 4월 9일부터 16일까지 8일 동안 $\mathrm{IMO}$ 가 새로 제정한 '자발적회원 국감사제도'(Voluntary IMO Member State Audit Scheme : 이하에서는 'VIMSAS'라 한다)에 따라 해양안전행정전반에 대 한 감사를 받게 되었다.

한편 이 감사제도의 효과를 극대화하기 위해서는 제도의 강제성 확보가 필수적이었으나 개발도상국들의 반대에 부딪 치게 되었다. 이로 인해서 동 제도는 기국의 역할을 이미 잘 수행하고 있는 선진해운국만 감사요청을 하고 감사실사가 실 질적으로 필요한 국가에서는 이루어지지 못하는 문제점을 가 지게 되었다. 이에 따라 $\mathrm{IMO}$ 의 '기국협약준수 전문위원 회'(Sub-Committee on Flag State Implementation : 이하에 서는 'FSI'라 한다)에서는 일부 국가들을 중심으로 VIMSAS 를 강제화하자는 주장이 제기되어, 2009년 11월 IMO 제26차 총회에서 VIMSAS의 제도화 및 강제화를 위한 결의서 A.1018(26)을 채택하였고, 현재는 2015년에 강제화를 목표로 $\mathrm{MAS}$ 의 골격 및 시행방법 등에 대한 논의가 진행 중이다 (IMO, 2010).

$\mathrm{MAS}$ 의 강제화는 각종 협약의 효과적인 이행을 보장하는 장치가 될 것으로 예상되고 있으며, 이에 대한 적극적인 대응 이 필요하다. 특히 해기교육과 관련하여 2012년 1월에 발효된 STCW 협약 2010 마닐라 개정규정은 해기사의 해기능력, 훈 련 및 자격에 관한 변경·추가사항을 포함하기 때문에 각국의 해기교육기관 ${ }^{1)}$ 은 교육과정 및 교과과정에 이를 반영해야 한 다. 더욱이 2015년부터 강제적으로 시행될 예정인 MAS에 대 비하여 협약의 회원국, 항만국, 연안국, 기국은 사전에 이에 대한 대응을 하여야 하며, 특히 해기사를 양성하고 있는 $\mathrm{STCW}$ 협약의 회원국 지정교육기관에서는 교육과정의 개편 등 각종 협약 이행사항을 사전에 철저히 검토할 필요성이 있 다.

따라서 이 연구에서는 우선 MAS의 개요에 대해 살펴보고, $\mathrm{MAS}$ 의 감사기준으로 사용하고 있는 강제협약 이행코드를 중심으로 $\mathrm{MAS}$ 강제화에 따른 당사국의 의무와 책임에 대해 검토해 보기로 한다. 또한 STCW 협약 2010 마닐라 개정규정 에서 해기사의 직무능력 및 자격에 관한 개정사항을 검토한 후, 해기교육체제를 강화하기 위하여 해기교육기관의 대응방 안에 대해 제안하고자 한다.

\section{MAS의 일반적 개요}

\section{1 의의}

$\mathrm{MAS}$ 는 해양안전을 확보 - 강화하기 위해 IMO 협약의 일 관되고 효과적인 시행과 협약체약국들에 의한 전 지국적인 협약이행을 감사하는 것을 말한다.

이 제도의 목적은 IMO 협약의 국내법 수용실태, 행정조직 - 인력의 배치현황, 정부권한 대행기관에 대한 감독체계 등의 검사결과로부터 도출된 문제점의 개선을 통해 전 회원국의 지속적이고 효과적인 국제협약 이행으로 선박안전을 확보하 고 해양환경을 보호하고자 하는데 있다.

감사 대상기관은 국제협약을 시행하는 정부기관과 정부업무 를 위탁받아 대행하는 정부대행기관이고, 감사 착안사항은 체 약국 - 기국 - 연안국 - 항만국 정부의 역할로 (1) 협약이행을 위한 법령체계, 관련 절차 및 세부 기술지침서 확보, (2) 관련 기구 및 전문 인력 확보, 훈련제도, (3) 정부업무대행기관에 대 한 지도감독체제 확립 및 이행이다.

\section{2 도입과정}

$\mathrm{IMO}$ 의 $\mathrm{MAS}$ 는 자발적인 감사제도로 출발하고 있으나 2004년 11월 캐나다 밴쿠버에서 개최된 유럽지역 PSC MOU(Paris MOU) 및 아 - 태지역 PSC MOU(Tokyo MOU) 회원국의 통합장관회의에서 채택한 결의사항 "IMO의 회원국 이 $\mathrm{IMO}$ 가 시행하는 $\mathrm{MAS}$ 에 실패하고, 그 개선조치를 취하지 않은 경우 당해 회원국의 선박에 대하여는 상당한 PSC점검 을 받지 않는 한 입항을 금지하는 제도의 도입”에 대해 검토 하였다.

$\mathrm{IMO}$ 의 FSI 위원회에서도 일부 국가들을 중심으로 $\mathrm{MAS}$ 를 강제화하자는 주장이 제기되어, 2009년 IMO 제26차 총회에서 “자발적인 $\mathrm{IMO}$ 회원국 감사제도”의 규정화 및 강제화를 위한 결의서 A.1018(26)「자발적인 $\mathrm{IMO}$ 회원국 감사제도의 계속 적 발전」을 채택함에 따라 현재는 2015년 회원국감사제도의 강제화를 목표로 준비 작업이 계속 진행 중이다2).

\section{3 감사절차}

$\mathrm{IMO} \mathrm{MAS}$ 의 감사절차는 크게 감사계획의 수립 및 감사시 행과 부적합사항 처리 및 후속조치 등으로 대별할 수 있으며, 각 단계별 절차와 주요 내용은 다음과 같다(Lee, 2011).

1) 현재 우리나라의 해기교육기관은 정규교육기관과 재교육기관으로 구분할 수 있다. 정규교육기관은 대학교와 고등학교로 다시 구분할 수 있 으며, 재교육기관으로는 한국해양수산연수원이 있다.

2) 제20차 FSI위원회(2012. 3.), IMO 강제협약 이행코드(III Code) 개발, 2015년까지 강제협약 이행코드 제정 시행을 위한 III Code(IMO Instruments Implementation Code; IMO 회원국감사 제도 시행을 위한 감사기준) 채택 방안 관련 옵션(시나리오 1 3 번) 논의. (결과) 편의 치적국의 강력한 요구로 III Code 발효시점이 가장 늦은 시나리오 3번(총회 28차(2013. 11.) III Code 채택 $\rightarrow$ MSC 94('14.5), MEPC 66('14.3) 관련 협약 개정안 채택 $\rightarrow$ 회원국 수락 절차 $\rightarrow$ '16.1.1 발효)으로 추진 결정함(Ministry of Land, Transport and Maritime Affairs, 2012). 
이윤철 · 박성호

1) 감사계획의 수립 및 시행

$\mathrm{IMO}$ 는 회원국들로부터의 신청에 따라 연간 감사계획을 수 립한 후 당해 회원국에 그 일정을 통보한다. 감사대상 회원국 이 정해지는 대로 사무총장이 임명한 감사팀장은 회원국과 감사진행에 관하여 일반적인 협의를 한다. 그 후 $\mathrm{IMO}$ 사무총 장과 회원국은 자발적인 신청에 따라 감사가 진행된다는 취 지의 협정서에 서명을 한다. 또한 감사팀장은 정부기구 및 조 직도, 관련 인력, 등록선박 현황, 협약가입, 정부업무 위임현 황, 해양사고 체제, 항만국통제 체제 등 일반적인 정보를 습득 하기 위한 설문서를 신청국가에게 보낸다. 1995년 STCW 개 정협약에 의한 선원교육훈련에 관한 감사 시, 5 명의 감사관으 로 구성된 바가 있고 $\mathrm{MAS}$ 시범감사에서는 3 명의 감사관으로 구성된 바가 있다. 감사관의 자격은 ISO 19011 또는 관련 ISO 기준에 적합하여야 하며, IMO 6개 공식 언어인 아랍어, 중국어, 영어, 불어, 러시아어 및 스페인어 중 하나에 대한 완 전한 구사능력을 갖추어야 하고, 지역적 배분에 의하여 결정 된다.

감사는 시작회의로서 시작되며, 이 회의에서 감사에 필요한 협조사항, 방문지 선정 등 세부 실무사항을 협의한다. 감사는 감사 착안사항 점검표에 의하여 진행되며, 서류조사와 인터뷰 를 병행하여 실시한다. 부적합시항이 발견되면 피감사국가의 관계자와 협의한 후 세부내용을 기록하고, 시정조치를 위하여 상호 정보제공을 한다.

2) 부적합사항 처리 및 후속조치 등

감사가 종결되면 종결회의가 개최되는데, 이 회의에서는 중간보고서에 포함될 발견사항, 관찰사항 및 부적합사항의 발 표와 지방관청이나 기타 관련기관의 방문에 대한 정보, 피감 사국의 시정조치 계획 및 조치사항, 최종보고서 작성 등에 관 한 내용이 논의된다.

감사팀장은 종결회의 후 중간보고서를 작성하여 피감사국가 에 송부하며, 피감사국가는 중간보고서를 수령한 후 90일 내 에 시정계획을 $\mathrm{IMO}$ 사무총장에게 제출한다. 이 과정에서 감 사팀은 피감사국가와의 사이에 의견이 일치하지 않은 사항이 있을 경우, 이를 해결한 후 최종보고서를 작성하여 피감사국 가에 전달한다. 감사종료 후 감사팀은 요약보고서를 작성하여 피감사국에게 송부하여 의견을 들은 후 회원국들에게 회람한 다. 초기감사에서 지적된 개선사항이나 추후 모니터링이 필요 한 문제들을 확인하기 위하여 감사 후 1 2년 사이에 후속감 사를 시행된다.

\subsection{MAS 시행을 위한 적용협약}

$\mathrm{IMO}$ 가 MAS의 시행을 위해 개발된 도구 문서로는 $\mathrm{IMO}$ 자 발적 회원국감사를 위한 기본지침(Framework for the
Voluntary IMO Member State Audit), IMO 자발적 회원국감 사를 위한 절차(Procedures for the Voluntary IMO Member State Audit Scheme) ${ }^{3)}$, IMO 강제협약 이행코드(Code for the Implementation of Mandatory IMO Instruments)가 있다. $\mathrm{IMO}$ 강제협약 이행코드는 전 세계적인 해양안전과 해양환경 보호를 증진시키기 위하여 IMO 협약에서 요구하고 있는 협 약 체약국, 기국, 연안국 및 항만국의 의무사항을 식별하여 제 시하는데 있으며, 이를 $\mathrm{MAS}$ 의 감사기준으로 사용하기로 하 였다.

감사의 대상이 되는 $\mathrm{MAS}$ 적용협약은 (1) 1974년 해상에서의 인명의 안전을 위한 국제협약과 1978년, 1988 년 의정서 (SOLAS 협약 1974, 1978 및 1988년 Protocol), (2) 1973년 선 박으로부터의 오염방지를 위한 국제협약에 관한 1978년 의정 서(MARPOL 73/78), (3) 1978년 선원의 훈련 - 자격증명 및 당 직근무 기준에 관한 협약(1978 STCW), (4) 1966년 국제만재 흘수선협약과 1988년 의정서(1966 LL, 1988 LL Protocol), (5) 1969년 선박의 톤수측정에 관한 국제협약(1969 TONNAGE Measurement), (6) 1972년 국제해상충돌방지규칙(1972 COLREG) 등 6 개의 협약이다. 또 이들 6 개의 협약을 근간으 로 관련 협약과 결의서 등이 추가로 $\mathrm{MAS}$ 에 적용된다고 하겠 다.

\section{MAS 시행을 위한 강제협약 이행코드 및 성과평과제도}

\subsection{IMO 강제협약 이행코드}

$\mathrm{IMO}$ 강제협약 이행코드는 $\mathrm{IMO}$ 의 $\mathrm{FSI}$ 위원회가 전 세계적 인 해양안전과 해양환경보호를 증진할 목적으로 주관청의 협 약 의무사항에 대한 이행을 돕기 위하여 제정한 것이다. 이 코드는 IMO 협약에서 요구하고 있는 협약 체약국, 기국, 연 안국 및 항만국의 의무사항을 식별하고 있으며, 협약 이행의 무사항 이행을 돕기 위한 추가적인 사항들을 담고 있다. 또한 이 코드는 $\mathrm{MAS}$ 의 감사기준으로 사용하기로 하고, MAS에 적용되는 3 가지 기본적인 도구문서 중의 하나로 채택되었다. 이에 따라 MAS는 총회 결의서 A.996(25)으로 채택한 $\mathrm{IMO}$ 강제협약 이행코드에서 요구하고 있는 사항을 중심으로 각국 이 강제협약을 이행하고 있는지 여부에 대해 감사를 실시하 게 된다. 이 코드에서는 공통적으로 적용되는 감사기준(제 1 편), 기국에 적용되는 감사기준(제2편), 연안국에 적용되는 감 사기준(제3편), 항만국에 적용되는 감사기준(제4편)을 제공하 고 있다. 또한 코드의 부속서에는 해당 $\mathrm{IMO}$ 강제협약상의 당 사국, 기국, 연안국, 항만국의 의무를 구분하여 각각 표로서 제공하고 있으며 회원국감사 시 이러한 의무에 대한 이행여

3) MAS를 실시하는데 필요한 감사의 준비, 실제 감사 및 보고 요건에 대한 절차를 기술하고 있다. 감사절차는 다음 4가지 부속서를 첨부하고 있다. (1) 협력각서 모델(Model Memorandum of $\mathrm{Co}^{-}$operation), (2) 사전 감사질의서(Pre-audit Questionnaire), (3) 감사제도 활동 순서 (Audit Scheme Sequence of Activities), (4) 감사보고서 부록 서식(Model Appendix forms for Audit Reports) 
부를 확인하고 있다(IMO, 2007).

\section{$3.21 \mathrm{MO}$ 강제협약 이행 성과평과 제도}

$\mathrm{IMO}$ 강제협약 이행코드는 대상 강제협약에서 요구하는 국 제적 의무를 달성하는데 있어서의 국가의 효용성에 대한 지 속적인 검토와 검증을 규정하고 있다. 따라서 정부는 국제협 약에서 요구하는 정부의 의무 사항이 제대로 이행되고 있는 지에 대하여 행정절차, 인력, 자원 등을 대상으로 정기적으로 성과를 평가하여야 한다(해양수산부, 2006). 이에 우리나라는 2007년 VIMSAS 준비대책의 일환으로 중앙정부 조직차원에 서 최초로 ISO 9001 품질관리시스템4)을 도입하였다.

$\mathrm{IMO}$ 강제협약 이행코드에서는 평가방법에 대해서 구체적으 로 규정하고 있다. 먼저, 기국의 평가 및 검토사항으로 기국은 협약에서 요구되는 의무이행에 필요한 행정적 처리, 절차 및 자원의 이행에 관한 자신의 성과를 정기적으로 평가하여야 한다. 또한 인력, 자원 및 행정절차가 기국의 의무이행에 적절 한지 결정하기 위한 기국의 성과평가 방법에는 항만국통제 출항정지율, 기국검사 결과, 사고통계, 통신 및 정보 처리절차, 연간 멸실통계(추정전손 제외) 및 기타 성과지표가 포함되어 야 한다. 이에 대한 평가방법에는 (1) 일정기간 동안의 경향분 석을 위한 선대 멸실율 및 사고율, (2) 선대 대비 확인된 출항 정지 선박 척수, (3) 자국에서 발급한 증서 또는 배서증서를 소지한 사람의 부적합 또는 범행으로 확인된 수, (4) 항만국의 결함보고서에 대한 대응과 중재, (5) 심각한 사고에 대한 조사 와 교훈, (6) 사용가능한 재정적, 기술적 및 기타 자원, (7) 자 국선대에 대한 검사, 조사 및 통제 결과, (8) 직무상 사고 조 사, (9) MARPOL $73 / 78$ (개정 포함)상의 사고 및 위반 수, (10) 자격증서, 배서증서, 승인 등의 중지 또는 철회 수 등을 정기 적으로 검토하여야 한다. 둘째, 연안국과 항만국의 평가 및 검 토 사항과 관련하여 연안국 및 항만국은 $\mathrm{IMO}$ 강제협약상의 권리 행사 및 의무 준수에 대한 성과를 정기적으로 평가하여 야 한다(IMO, 2008).

\section{MAS의 대상, 원칙 및 당사국의 의무}

\section{1 감사대상}

감사대상을 실질적인 내용 면에서 대상협약을 중심으로, 그 리고 대상기관을 기준으로 살펴보면 다음과 같다.

$\mathrm{MAS}$ 에서 감사하고자 하는 실질적인 내용은 (1) IMO협약 등 $\mathrm{IMO}$ 의 강제규정에서 체약국 - 기국 - 연안국 - 항만국 정부에 게 부여한 698 가지 의무의 체계적인 국내 이행을 위한 법령체
계, (2) 선박안전 관리 및 해양환경 보호 등 해양안전관리 조 직 및 인력의 적정성 및 (3) 정부의무·권한을 민간기관에게 대행시킨 경우, 그 대행체제 및 지도 - 감독체제의 적절성 등 이 된다.

대상협약을 중심으로 볼 때 감사대상 협약에는 (1) 해상인 명안전협약(1974 SOLAS), (2) 해양오염방지협약(MARPOL $73 / 78)$, (3) 선원의 훈련, 증서발급 및 당직에 관한 국제협약 (1978 STCW), (4) 국제만재흘수선협약(1966 LL), (5) 국제톤 수협약(1969 TONNAGE Measurement), (6) 해상에서의 충돌 방지에 관한 협약(1972 COLREG)이 있다. 이와 같은 6가지의 협약과 관련한 의정서 및 관련 부속서 등도 감사대상에 당연 히 포함된다.

위 국제협약의 구체적 이행을 위한 하위 규칙으로 ISM Code, HSC Code, IMDG Code, IBC Code, BCH Code, IGC Code, STCW Code, INF Code, FSS Code, FTP Code, LSA Code, CSS Code, Grain Code, NOx Technical Code가 포함 되며, 기타 총회 - 해사안전위원회 - 해양환경보호위원회의 결 의서 등을 포함하여 총 33 가지의 $\mathrm{IMO}$ 강제규정(협약, 코드 및 결의서)이 감사대상에 포함된다(IMO, 2007).

대상기관을 중심으로 감사대상을 살펴보면, 우선 정부기관인 당시 해양수산부(당시 각 지방해양수산청, 중앙해양안전심판 원, 해양조사원) 및 해양경찰청 일부가 포함된다. 민간기관으 로서는 선박안전기술공단, 한국선급 및 한국해양수산연수원 등 정부권한 대행기관이 포함되나, 정부권한 대행기관의 경우 에는 정부권한 대행체제 파악 및 지도·감독관계를 파악하는 수준에 한정된다.

\section{2 감사원칙 (Framework for the IMO Member State Audit Scheme)}

$\mathrm{MAS}$ 에서는 회원국의 국제협약 이행 및 강제 정도를 측정 하고자 다음과 같은 분야에 대한 감사를 실시하게 된다(IMO, 2005).

(1) IMO 강제협약 이행코드 준수여부

(2) 해양안전 및 오염방지에 관한 국제협약의 국내 입법체계

(3) 법령 집행절차

(4) 해양안전 및 환경보호와 관련된 국제협약 상 의무사항의 이행을 위해 대행기관에게 권한을 위임한 절차 및 통제장 치

(5) 정부 및 대행기관의 검사 및 증서교부에 관한 회원국의 통 제, 감시 및 환류 장치

(6) 국제협약상 기타 의무사항 및 책임의 이행 정도

또한 $\mathrm{IMO}$ 가 각 회원국에 대한 감사과정 및 결과로부터 얻고 자 하는 구체적인 목적은 다음과 같이 정리될 수 있다(IMO,

4) 해양사고를 줄이기 위한 $\mathrm{IMO}$ 의 지속적인 해양안전 - 해양환경에 관한 국제협약 강화에 맞추어 해양안전 분야에 대해서 다음의 목적과 함 께 국내 중앙행정부처 단위로는 최초로 ISO 9001:2000 품질경영시스템(Quality Management System : QMS)을 구축하고 인증을 추진하게 되었다. 21세기 국제화 시대에 맞는 QMS를 구축함으로써 국제적 위상 및 이미지 제고, 기존의 행정업무를 ISO 9001 국제표준에 맞게 시스 템화, 해양안전에 관한 핵심 프로세스의 정의 및 보강, 기타 표준의 작성 및 이행을 통한 해양안전서비스 강화를 목적으로 한다(MOMAF, 2006). 
이윤철 · 박성호

2005).

(1) 능력향상 촉진 및 관련 기술 지원을 통해 국제협약 상 정 부의무의 이행 독려

(2) 회원국에 대한 검사결과 제공으로 회원국의 협약 이행능 력 향상 기대

(3) 연차별 감사결과를 통합한 요약보고서의 전 회원국 회람 을 통해 MAS에서 도출된 일반적인 교훈의 폭넓은 공유

(4) 감사로부터 도출된 교훈의 체계적인 검토를 통해 $\mathrm{IMO}$ 의 규정 제정의 유효성 및 적절성 확보

위에서 일부 언급된 감사범위를 구체적으로 살펴보면, (1) $\mathrm{IMO}$ 강제협약의 국내 입법을 통한 이행 및 강제여부, (2) 협 약이행 및 강제를 위한 효과적인 통제 및 감시장치, (3) $\mathrm{IMO}$ 규정을 효과적으로 전파하기 위한 장치, (4) 국내 법령 위반사 항에 대한 강제조치 및 (5) 기타 관련 협약에서의 의무와 책임 이 될 것이다. 또한 $\mathrm{IMO}$ 강제협약의 이행 및 강제와 관련한 행정적, 법적 및 기술적 분야에 대한 감사의 최소범위는 (1) 관할권, (2) 조직 및 기구, (3) 법령체계, (4) $\mathrm{IMO}$ 강제협약 및 규정의 전파체계, (5) 강제절차, (6) 통제, 조사, 검사, 심사, 확 인, 승인 및 증서발급 체계, (7) 대행기관 및 지정검사원의 선 발, 인정, 권한부여, 권한위임 및 감시 체계, (8) IMO 보고사 항의 조사체계, (10) $\mathrm{IMO}$, 기타 정부 및 기구에 대한 보고체계 등이 될 것이다.

\section{3 당사국의 의무(감사기준)}

MAS 감사 당사국의 의무는 IMO 강제협약 이행코드에 다 음과 같이 기국, 연안국, 항만국으로 구분하여 구체적으로 규 정하고 있다(IMO, 2007).

\section{1) 기국의 의무 \\ (1) 기국의 이행사항}

첫째, 기국은 기국의 의무와 책임을 효과적으로 이행하기 위 하여 해양안전 - 오염방지협약 및 의정서 요건의 이행 - 강제 에 필요한 국내법령 및 지침의 발행을 통한 정책을 시행하여 야 하고, 주관청에 대해서 최신정책의 수립 및 개정책임을 부 여하여야 한다.

둘째, 기국은 해양안전과 환경보호 프로그램의 관리 수단 및 절차를 수립하여야 한다. 특히 STCW 협약의 요건 준수 여부를 확인할 수 있는 수단을 확보하여야 한다. 이와 관련하 여 코드에는 선원 훈련, 자격평가 및 증서발급 절차의 STCW 협약 준수여부, 증서 및 배서증서가 선원의 능력을 정확히 반 영하고 있는지 여부, 자국이 발급한 증서 또는 배서증서 소지 자의 불이행에 대한 공정한 조사수단 확보여부, 필요시 증서 나 배서증서의 효과적인 회수 - 중지 - 취소 수단 확보여부, 다 른 회원국의 법령에 의거한 훈련, 평가 및 증서발급 활동을 포함한 행정조치가 당해 기국이 자국 선박에 종사하는 선장, 사관 및 기타 선원의 자격을 보장하기 위한 책임을 부담하고 있는지 여부 등을 확인할 수 있는 수단을 확보하여야 한다.
셋째, 자국 선박에 대하여 $\mathrm{IMO}$ 의 최소승무정원 원칙에 따 른 배승을 담보할 수 있어야 한다.

\section{(2) 권한의 위임}

첫째, 기국은 정부권한 대행기관(Recognized Organization) 의 효율적인 통제를 위해서 $\mathrm{IMO}$ 결의서에 규정된 대행기관 의 최소요건에 따라 대행기관이 수임업무를 수행할 기술, 관 리 및 연구능력을 보유하고 있는지의 여부를 점검하여야 하 고, 최소한 $\mathrm{IMO}$ 결의서 또는 동등한 법령에서 규정된 요소를 포함하는 주관청과 대행기관 사이의 공식적인 서면협정을 체결하여야 한다. 또한 국내법령 및 해석을 대행기관에게 제 공하고 협약요건을 상회하는 주관청의 기준을 상세히 열거하 며, 대행기관에게 주관청의 협약규정 해석을 돕기 위한 자료 를 제공하기 위한 기록유지를 요구하여야 한다.

둘째, 기국을 대신하여 검사 및 점검을 수행할 검사원을 지 정한 경우, 당해 검사원에 대한 적절한 통제수단 확보하여야 한다.

셋째, 기국은 대행기관에 대해서 자국 선박이 실제로 IMO 강제협약과 협약요건을 보충하는 국내요건의 충족여부를 확 인하기 위한 보충적인 검사를 시행할 수 있는 권한 등이 포함 된 감시프로그램을 수립하여야 한다.

\section{(3) 강제사항}

첫째, 기국은 자국 선박 및 관할권 내의 조직과 인력이 국 제규정 및 기준을 준수하기 위한 수단을 확보하여야 한다. 이 러한 수단에는 국제규정 및 기준의 요건에 충족할 때까지 자 국 선박에 대한 출항금지 조치와 실제 자국 선박 및 선원이 적합한 증서를 소지하고 있는지 여부를 확인하기 위한 정기 적인 검사가 포함되어야 한다. 또한 선박의 전승무원이 안전 및 오염 관련 비상상황에 대처하기 위한 적절한 능력이 있는 지 여부를 확인하여야 하며, 자국 선박 및 선원이 국제규정 및 기준을 위반하였을 때 국내법상 적용 가능한 엄격한 벌칙 규정을 제정하여야 한다. 이와 더불어 기국은 위반한 자국 선 박 및 선원에 대한 조사 및 별도의 소송절차를 진행할 수 있 는 제도를 마련하여야 한다.

둘째, 기국은 신속하고 철저한 해양사고 조사결과와 취약분 야 발굴을 위한 경향분석이 가능한 통계자료를 제공하고, 항 만국이나 연안국으로부터 보고된 결함사항 및 오염사고에 대 한 즉각적인 대응을 위한 통제 및 감시 프로그램 개발 - 이행 하여야 한다.

셋째, 기국은 국내입법을 통한 관련 IMO 협약의 이행확보 를 하여야 하며, 조사 및 검사인력을 포함하여 국내입법을 이 행하고 강제할 자격이 있는 적절한 수의 인력을 제공하여야 한다. 또한 항만국에 의해 억류된 자국선박에 대한 조사를 수 행할 자격이 있는 충분한 수의 기국 인력을 제공하여야 한다.

넷째, 기국은 외국 항만국에 의해 출항정지된 자국 선박의 결함사항에 대한 즉각적인 시정조치를 이행 - 감시하여야 한 다. 
다섯째, 기국 또는 대행기관은 선박이 모든 해당 요건을 충 족한다고 판단된 경우에만 당해 선박에 대하여 국제증서를 발급하거나 배서하여야 한다.

여섯째, 기국은 선원이 모든 해당 요건을 충족한다고 판단된 경우에만 당해 선원에게 국제자격 증서를 발급하거나 배서하 여야 한다.

\section{(4) 기국의 조사활동}

해양사고 조사는 적합한 자격을 갖추고 해양사고 관련 문 제에 정통한 조사관에 의해 수행되어야 하며, 기국은 해양사 고나 오염사고의 발생장소에 관계없이 위와 같은 조사를 수 행하기에 적합한 자격 있는 조사관을 투입할 준비가 되어 있 어야 한다. 그리고 기국은 자국 선박에서 직무상 사고나 재난 으로 3일 이상의 휴무가 요구되는 인명 부상사고 및 사망사고 가 발생한 경우, 관련 $\mathrm{IMO}$ 협약 및 $\mathrm{IMO}$ 에 의해 개발된 지침 에 따라 이를 조사하여 그 결과를 보고하여야 한다.

\section{(5) 평가와 검토}

기국은 협약에서 요구되는 의무이행에 필요한 행정적 처리, 절차 및 자원의 이행에 관한 자신의 성과를 정기적으로 평가 하여야 한다. 이에 대한 평가 기준은 앞에서 설명한 IMO 강 제협약 이행 성과평가 제도에 따른다.

2) 연안국의 의무

(1) 연안국의 이행사항

연안국은 각종 $\mathrm{IMO}$ 강제협약에 규정된 의무의 이행과 강 제에 필요한 정책 및 지침을 이행하여야 한다. 이를 위해 필 요하다면, 채택된 관련 정책의 최신화 및 개정을 위한 주관청 내의 책임을 부여하여야 한다.

\section{(2) 강제사항}

연안국은 자국의 권리행사 및 의무준수와 관련된 국제규정 을 준수하여야 한다. 또한 연안국은 취약분야 식별을 위한 경 향분석이 가능한 통계자료 제공, 관할수역에서 발생한 오염사 고에 대한 즉각적인 대응, 해양사고 조사와 관련한 기국 및/ 또는 항만국과의 협력을 위한 통제 및 감시 프로그램 개발 이행하여야 한다.

\section{(3) 평가와 검토}

연안국은 $\mathrm{IMO}$ 강제협약 상의 권리행사 및 의무준수에 대 한 성과를 정기적으로 평가하여야 한다.

\section{3) 항만국의 의무 \\ (1) 강제사항}

항만국은 자신의 권리행사 및 의무준수와 관련된 국제규정 을 준수하여야 한다. 항만국은 PSC 권한을 행사함에 있어서 $\mathrm{IMO}$ 가 채택한 관련 결의서에 의거하여 $\mathrm{PSC}$ 프로그램 집행 절차를 수립하여야 한다. 이러한 $\mathrm{PSC}$ 는 $\mathrm{IMO}$ 가 채택한 관련
결의서에 따라 권한 있고 자격 있는 $\mathrm{PSCO}$ 에 의해서만 수행 이 가능하다.

(2) 평가와 검토

항만국은 국제협약상의 권리행사 및 의무준수에 대한 성과 를 정기적으로 평가하여야 한다.

\section{MAS 강제화에 대비한 해기교육기관의 대응방안}

\subsection{MAS 강제화에 대비한 해기교육체제의 강화방안}

2015년 MAS 강제화를 목표로 IMO FSI 전문위원회에서는 강제협약 이행코드에 대한 세부작업을 진행하고 있다. 이러한 상황에서 해기교육기관에서는 STCW 협약 2010 마닐라 개정 규정의 이행과 관련하여 적절한 준비가 필요한 실정이다. 즉, 동 개정규정에서 당사국 정부에게 요구하는 사항들은 결국 해기교육기관에서 준비해야 될 사항이기 때문이다. 이와 같은 당사국 정부에 요구하는 사항들은 2012년 FSI 20차 통신작업 반 보고서의 Annex 5에 식별이 되어 있다. 특히 STCW 협약 2010 마닐라 개정규정의 발효에 따라 개정규정에 반영되어 있는 내용을 국내의 법제에 신속하게 도입되어야 하는 바, 선 원법, 선박직원법, 선박안전법, 국제항해선박 및 항만시설 보 안에 관한 법률 등이 신속하게 개정 - 발효되어야 할 것이다. 이러한 입법과정을 통해 해기교육체제를 강화할 수 있는 제 도적인 방안은 결국 국제법으로서의 STCW 협약과 국내법으 로서의 선박직원법 및 행정고시로서의 해기품질기준 및 지정 교육기관기준에서 규정하고 있는 해기품질평가제도를 통한 엄격한 인증제도의 도입이 될 것이다. 이는 $\mathrm{MAS}$ 의 당사자이 며 협약당사국인 대한민국 정부의 국제법 준수 의무이고, 이 에 따라 국가기관인 우리나라 해기교육기관은 교육현장에서 $\mathrm{STCW}$ 협약에 따라 세계 최고의 유능해기사를 양성할 수 있 는 교육시스템을 구축하여야 할 것이다. 이를 위해서 모든 해 기교육기관은 국제법 및 국내법에 따른 해기교육의 이행여부 를 검증할 수 있는 보다 철저한 해기품질 평가제도를 실시하 여야 할 것이다.

\subsection{STCW 협약 2010 마닐라 개정규정에 대비한 교육과정 의 개선방안}

1) 서설

해기교육은 원칙적으로 STCW 협약에 따라 운항급, 관리 급으로 구분되어 이루어진다. 따라서 한국해양대학교와 같은 대학의 해기교육기관의 경우 운항급과 관리급 교육과정을 망 라하여 교육이 이루어지고 있는 바 STCW 협약의 모든 내용 을 준수하여야 한다. 특히, 1978년 STCW 협약의 1995년 개 정규정 및 2010 마닐라 개정규정이 모두 발효한 상황이므로 
이윤철 · 박성호

이를 전면적으로 교육과정에 반영하여야 한다. 따라서 해기교 육을 담당하고 있는 대학은 물론 고등학교, 단기양성을 담당 하고 있는 한국해양수산연수원 등에서는 지금까지 1995년 개 정규정에 따라 해기교육과정을 운영해 왔으나, 대부분이 2010 년 개정규정을 아직 반영되어 있지 않은 상황이므로 조속히 현 교육과정을 개정하여 반영하여야 할 것이다. 특히, 2010년 개정규정은 2013년 7월 1일 이후 입학하는 학생들에게 강제 로 적용되므로 2013년 상반기 중으로 개정하여 사전에 대비 하여야 할 것이다. 이 논문에서는 우리나라 해기교육기관에서 새로이 교육과정에 반영하여야 할 내용을 2012년 1월 발효된 마닐라 개정규정에 따라 다음과 같이 제시하고자 한다(Youn and Seong, 2010).

\section{2) 항해사 양성분야}

1995년 개정규정은 ECDIS(Electronic Chart Display)를 해 도의 범주 안에 포함시키고 있으나, 2010년 개정규정은 $\mathrm{ECDIS}$ 의 운용능력을 당직근무를 위한 필수 과목으로 규정하 였다. 요구되는 지식 및 능력은 기기의 특성과 효용성 및 한 계에 대한 이해, 기기의 운영, 정보의 획득과 분석 및 해석 등 이며, 교육 방법은 이론적 이해와 더불어 실제 항해 상황을 구현할 수 있는 시뮬레이터 훈련을 권고하고 있다. 따라서 교 육과정은 독립 교과목, 지문항해학 또는 항해기기학에 배치하 거나 지문항해학에서는 운용을, 항해기기학에는 기술적 이해 와 관련된 내용을 포함할 수 있을 것이다. 또한 승선실습 이 전에 기초적인 운용 능력을 갖출 수 있도록 시뮬레이션 실습 및 관련 과목의 신설이 필요하다.

또한, 1995년 개정규정에서는 $\mathrm{BRM}$ (Bridge Resource Management)을 Code $\mathrm{B}$ 편에 권고적 지침을 제공하였으나, 2010년 개정규정에서는 관련 내용을 코드 A편에 규정하여 교 육 훈련을 강제화 하였다. 협약에서는 선교자원의 할당과 과 업의 우선순위, 당직자간의 효과적인 의사소통, 통솔력, 상황 을 파악하고 유지할 수 있는 능력 등을 포함한 선교자원관리 원리에 대한 이해를 교육과정의 구성요소로 하고 있다. $\mathrm{BRM}$ 교육은 현재 일부 선사 및 교육기관에서 프로그램을 개발하 여 시행하고 있으며, 대학 등 해기교육기관은 자체적인 프로 그램을 개발하여 훈련을 통해 개정규정에 대비하여야 할 것 이다. 교육방법은 학기 교과목으로 배치하거나 단기 집중과정 의 형태로 운영할 수 있을 것이다.

그리고 선박교통관리(Vessel Traffic System : VTS)에 관 한 절차와 통신능력과 관련하여, 해사통신영어에서 정보 전달 에 관한 표준 구문을 다루고 있으며, 지문항해학 과목에서 항 해계획 분야에서 VTS 부분을 추가할 수도 있겠다. 이 내용은 현행 교과목에서 약간의 보완이 이뤄진다면 2010년 개정규정 의 요건을 충족하는데 문제가 없을 것이다.

통솔력과 단체작업 기술(Application Of Leadership And Team Working Skills)의 적용과 관련하여 2010년 개정규정 에서는 교육과정에 의무사항으로 도입하고 있다. 당직을 비롯
한 선박에서의 업무는 여러 사람의 공동작업에 의해 이뤄지 는 경우가 많다. 특정 작업에 대해 업무의 내용을 분석하고, 각 업무에 적절한 진행과정을 관리함으로써 성공적으로 업무 를 종결시키는 일련의 과정을 교육훈련을 통해 효율화 하고 자 하는 내용이 교육의 요목으로 제시되어 있다. 현재 이와 유사한 과목으로 해기전문직론이 있으나 특정학과에서 다루 고 있는 교육과정으로 통합된 교재 개발 및 현장에 적용될 수 있는 실무적 교재의 개발이 시급히 필요하다. 이 내용의 성격 은 상당 부분 $\mathrm{BRM}$ 에서 요구하는 지식범위와 유사하므로 두 주제를 통합하여 교재를 개발하는 방안이 요구된다.

한편, 인명과 선박의 안전에 관한 기여(Contribution To The Safety Of Personnel And Ship) 분야에서는 해상비상대응실 습, 의료관리, 선박보안 및 안전관리실습 과목과 같이 기존의 교과목으로 충분히 2010년 개정규정의 요건을 충족할 수 있 다. 수색구조 교육내용의 변경과 관련하여, 1995년 개정규정 은 수색구조에 대한 교육내용을 상선의 수색구조에 관한 (Merchant Ship Search And Rescue : MERSAR) 지침을 기 반으로 하도록 되어 있으나, 2010년 개정규정은 국제항공해양 수색구조(International Aeronautical And Maritime Search And Rescue : IAMSAR)를 지침으로 하도록 개정되었으므로 이에 따른 교과목의 개정이 필요하다. 시각신호방식에 의한 정보의 송수신과 관련하여, 2010년 개정규정에서 추가된 국제 신호서의 'I자 신호(Single Letter Signal) 및 국제해상충돌방 지규칙 부속서 4 에 의한 신호에 대해 교육과정의 보완이 필요 하다.

\section{3) 기관사 양성분야}

2010 년 개정규정에서 기관사 양성분야의 가장 중요한 개정 내용은 전자전기사(Electro Technical Officer)의 교육과정 신 설이다. 전자전기사는 2010년 개정규정에서 신설된 해기직종 으로 운항급만을 두고 있으며, 기관실을 중심으로 통신 및 항 해기기에 이르기까지 선내의 모든 전기, 전자 기기의 정비를 담당하는 직원이다. 그 교육과정은 기관사 교육과정과 같이 6 개월 이상의 승선실습과 육상공장실습을 요구하고 있으며 교 육과정의 유형은 다음과 같이 두 가지의 과정으로 구성해 볼 수 있을 것이다. 첫째, 기관분야 학부에서 전기 - 전자를 부전 공으로 하는 자가 이 면허를 취득하여 항해사의 통신면허의 형태와 같이 복수 면허 소지자로서 승선하는 경우를 생각할 수 있다. 둘째, 전기-전자를 전공으로 하는 자가 기관분야에 관한 일정 교과목을 이수하고, 승선실습을 거쳐 면허를 취득 하게 하는 경우를 생각할 수 있다.

또한, 기관실 자원관리(Engine Room Resource Management : ERM) 및 통솔력과 단체작업 기술의 적용과 관련하여, 이 분야는 항해사 교육과정의 $\mathrm{BRM}$ 과 통솔력 및 단체작업 기술의 적용분야와 유사하므로 각 해기교육기관에 서 시행하고 있는 관련 교육과정을 개정하거나 신설이 필요 하다. 


\section{4) 공통분야}

1995년 개정규정에 따라 해기교육기관에서는 탱커 기초교 육과정을 운영하고 있다. 과거의 탱커 기초교육은 유류 탱커, 화학물 탱커, GAS 탱커의 구분이 없이 이뤄졌으나, 2010년 개정규정은 유류와 화학물 탱커는 함께 교육할 수 있으나 GAS 탱커에 대한 기초교육은 별도로 요구하고 있으므로 이 에 대한 대응이 필요하다.

탱커를 유조선·케미컬탱커(제 $\mathrm{V} / 1-1$ 조)와 액화가스탱커 (제 V/1-2조)로 구분하여 탱커교육을 실시하도록 규정하고 있 으며, 이를 탱커기초교육과 탱커직무교육으로 구분하고 있다. 특히 탱커직무교육을 이수하기 위해서는 (1) 탱커기초교육증 명서를 소지할 것, (2) 해당 선종 탱커에 3개월 이상 승인된 승무경력이 있거나 또는 예비원의 자격으로 승선하여, 승인된 훈련기록부에 3 회 이상 적양하작업을 수행한 기록을 포함한 1 개월 이상 승인된 승무경력이 있을 것, 그리고 (3) 탱커화물 작업교육과정을 이수하고, 소정의 시험에 합격할 것 등을 요 구하고 있다. 따라서 졸업 후 LNG 등의 선박에 승무하기 위 해서는 최소한 3 개월 이상의 동일분야 선박에 승무한 경력이 있어야만 가능하다는 점이 특이한 점이다.

따라서 해기교육기관에서는 탱커교육을 기초교육과 직무교 육으로 구분하여 교육과정에 반영하고 기존의 교과목을 개정 하여야 한다.

\section{6. 결 론}

$\mathrm{UN}$ 과 $\mathrm{IMO}$ 를 중심으로 하는 국제해운사회에서는 각국의 해운 규모 발전에도 관심을 가지고 있지만, 주된 관심은 관련 국제협약에서 요구하는 체약국들의 국제적 의무이행이다. 특 히, 대형 오염사고를 유발하는 선박사고가 연이어 발생하고 있어 이를 예방하기 위한 다각적인 노력을 강구하고 있다.

그 동안 $\mathrm{IMO}$ 에서는 해상안전 및 선박으로부터의 해양오염의 방지와 통제에 관한 각종 협약과 관련 지침 등을 제정 및 개 정하여 시행해 오고 있다. 이러한 국제해사협약은 50 여개가 넘으며 방대한 양의 관련 지침들이 $\mathrm{IMO}$ 에서 다루어지고 있 다. 이처럼 $\mathrm{IMO}$ 에서는 해양사고를 방지하기 위해 꾸준히 노 력해 왔으며, 특히 지난 10 여 년간 다양한 조치들을 개발하여 시행해 왔다. 이렇게 보다 안전하고 깨끗한 해상환경을 확보 하려는 IMO 및 회원국들의 노력에도 불구하고 인명 및 해양 환경에 관련된 대형 선박사고가 빈번히 발생해 왔고, 국제사 회는 $\mathrm{IMO}$ 가 제정한 각종협약의 유효성에 의문을 제기하여 왔다. 더욱이 세계 각국은 $\mathrm{PSC}$ 등을 통한 규제를 강화하고 있음에도 불구하고 기준미달선으로 인한 해양사고는 계속해 서 발생하고 있는 현실이다. 이로 인해 최근 들어서는 사고방 지를 위해 궁극적으로 선박의 기국이 제 역할을 해야 한다는 데 착안을 하고 회원국들의 해양안전 관리능력에 대해 감사 를 시행하는 $\mathrm{MAS}$ 의 강제화라는 고단위 처방을 강구하기까 지 이르게 되었다.

이러한 $\mathrm{IMO}$ 의 노력과 더불어 우리나라는 $\mathrm{IMO} \mathrm{A}$ 그룹 이
사국으로서 2007년 VIMSAS 수감 시 IMO에서 요구하는 기 국, 항만국 및 연안국의 의무사항에 대하여 분명한 인식을 가 지고 노력하고 있음을 인정받았지만, 2015년부터 강제화되는 $\mathrm{MAS}$ 에 선제적으로 대응하여 해양안전 선진국으로 위상을 확고히 하여야 할 것이다.

이에 대한 대응방안으로 기국, 연안국, 항만국의 의무 이행 뿐만 아니라 기국 및 체약당사국의 의무를 현장에서 준수하 는 역할을 하는 관련기관의 역할 또한 필수적이다. 특히 $\mathrm{STCW}$ 협약을 담당하는 해기교육기관의 해기교육과 훈련의 의무는 성실히 이행되어야 하고, 이는 곧 기국이나 체약당사 국의 협약준수의무가 될 것이다. 따라서 해기교육기관에서는 이러한 국제법 및 국내법적인 해기교육체제를 더욱 면밀히 연구하여 신속히 도입하여야 하는 바, 그 검증방안으로서 해 기품질평가의 성실한 시행이 필수적이고, 이는 곧 $\mathrm{IMO}$ 해사 협약 체약국으로서의 국제해사협약의 준수가 될 것이다. 특 히, 2010년 개정된 STCW 마닐라 개정은 지난 2012년 이미 발효되었으므로 해기교육기관에서는 2013년 상반기 중으로 교육과정을 개정하여 2014년 입학생부터 적용하여야 할 것이 다.

\section{참 고 문 헌}

[1] IMO(2005), FRAMEWORK AND PROCEDURES FOR THE VOLUNTARY IMO MEMBER STATE AUDIT SCHEME(Resolution A.974(24)).

[2] IMO(2007), CODE FOR THE IMPLEMENTATION OF MANDATORY IMO INSTRUMENTS, 2007(Resolution A.996(25)).

[3] IMO(2010), FURTHER DEVELOPMENT OF THE VOLUNTARY IMO MEMBER STATE AUDIT SCHEME(Resolution A.1018(26)).

[4] Lee, Y. C.(2011), International Maritime Conventions, pp. $161-164$.

[5] Ministry of Land, Transport and Maritime Affairs(2012), Maritime Safety News, No. 12-15. pp. 22-23.

[6] Ministry of Maritime Affairs and Fisheries(2006), ISO certified and IMO Member State Audit Scheme summary measures research report.

[7] Youn, M. O. and Seong, Y. C.(2010), "A Study on the Review and Countermeasure for 2010 Amended Convention of the STCW", Journal of the Korean Society of Marine Environment \& Safety, Vol. 16, No. 3, pp. 298-299.

\footnotetext{
원고접수일 : 2013년 02월 25일

심사완료일 : 2013년 03월 26일 원고채택일 : 2013년 03월 27일
} 